\title{
Brand Engagement: Insights and Learning from other Discipline
}

\author{
Muhammad Mansoor Zakir \\ Assistant Professor, Bahria University, Karachi Pakistan \\ Mansoor.zakir@gmail.com
}

\section{Doi:10.5901/mjss.2013.v4n11p609}

\begin{abstract}
Current study was undertaken to explore a new and emerging term "brand engagement". The main purpose of the research was to identify how male's involvement in video games could be used to create brand engagement among consumers. The study employed observation, in-depth interviews and survey to collect data from a group of male gaming enthusiasts Dominance, social interaction and masculinity are the factors that male gamers associate with gaming. The research explored that to attract the male market segment, brand managers need to incorporate attributes in their brand positioning that that creates anxiety, curiosity and attraction among them, attributes that motivates the consumers and shows them the challenges and goals of life.
\end{abstract}

Keywords: Brand Engagement, Dominance, Masculinity, Social Interaction, and Video Games

\section{Introduction}

"Engagement has been previously examined across a range of academic disciplines, including sociology, psychology, political science, and organisational behavior" (Ili'c, 2008) as cited by Hollebeek L. (2011). Engagement is not a new process. People have been engaged in many sorts of activities since ages, be it wine, company of people, sex or any other entertainment. Engagement as mentioned above has been studied in different contexts and disciplines; the concept has its theoretical foundations in psychology (Hollebeek, 2011). Personal engagement was defined as adoption of a work role during the work performance. People assume a particular role physically, emotionally and cognitively and disengage them when they uncouple themselves from the work (Kahn, 1990). The concept is only emerging in the marketing literature; it is being viewed as a useful construct to predict customer loyalty. (Bowden, 2009; \& Brodie et al's, 2010). The concept has been studied uni-dimensionally (Resnick, 2011), and multi-dimensionally (Frank, Finnegan, \& Taylor, 2004). The engagement concepts lack a universal conceptualization. It has been studies in different disciplines with different names, such as 'student engagement' (Skinner \& Belmont, 1999), personal engagement (Kahn, 1990), Customer engagement (Patterson, Yu, \&, De Ruyter, 2006), employee engagement (Green, 2007) and customer brand engagement.

Video games and computers are a very common type of an entertainment and their sole purpose is to keep the players engaged and involved. Game designers attract and maintain curiosity towards the game through the designs of computer and video games. (Jones, M. n.d.) Jones further elaborates that games provide the fun-based learning and it is an immersive activity. The paper focused on creating engagement in computer-based learning environment.

The concept of brand engagement has been defined by Hollebeek (2011) as a tripartite construct with cognitive, behavioral, and emotional engagement elements. The current study follows the definition as it has been rigorously worked upon and its relationship with other constructs has been discussed by the author extensively. Hollebeek (2011).

Jones, $M(n . d)$, however, provides a different definition in the context of games. The definition suggests that in the gaming-context, engagement refers to the notion that the learner (player) wants to be in the game. The paper bases the definition on Csikszentmihalyi (1990) flow theory. Flow refers to a stage where individuals feel they are in total control and it gives them a sense of exhilaration and enjoyment. The games are designed with the aim to be an immersive and fun activity. Game players become so deeply involved and engaged in the computer electronic games or video games that they lose interest in the real world around them. The game becomes their virtual world (Dickey, 2005). The main purpose of games, video or computer, is to provide entertainment but the strategies used in games intend to engage people in the game (Jones, M. n.d). The strategies and tactics used depend on the type of game but usually it includes role-playing, challenges, and interaction with others within the game. The study focuses on the factors that cause this engagement and learn it in the creation and augmentation of brand engagement. 


\section{Purpose of the Research}

Giselle Abramovich (2012) proposes that Brand engagement is a new phenomenon that requires certain attention. Kazakulova Y. \& Kuhn E. (2012) mention that the difference between ordinary and successful brands is the way brand engages its consumers. The purpose of the current research is to find and look for ways that can enhance the creation of brand engagement and involvement among consumers. The main objective is to find out the causes of people especially men getting engaged in games, what causes their involvement in e-games or video games and what are the reasons behind it and what gaming plans, strategies and tactics have been used by the gaming industry to create such deep involvement and how can the same strategies provide useful insights for creating brand engagement. The research seeks to learn from video gaming in the creation of brand engagement, and apply the same thing on consumers to make them engaged in brands in the same way as the game players are engaged in games.

\section{Research Problem}

People are obsessed with different things, be it sports, company of people, sex, games (electronic, video or computer). Males are especially obsessed with video games as discussed by Dickey (2005). The gaming industry has created engagement and involvement in a way that players feel being apart of the game. The current study seeks to find out why and how the gaming industry has created such an attraction for people and what useful insights brand managers can learn and applied in creating brand engagement.

\section{Research Objective}

Following are the research objectives of the current study:

1. To find out about male obsession with video games.

2. To find out the factor establishing a relationship between men and video games.

3. To find out ways to use the learning from video games in creating brand engagement.

\section{Research Questions}

In order to fulfill the research objectives, the study had the following questions.

1. Why are men so obsessed with video games?

2. What factors contribute to the creation of brand engagement?

3. How can these obsessions be applied on creating brand engagement?

\section{Significance of the Study}

The term "brand engagement" is defined as "the level of an individual customer's motivational, brand-related and context-dependent state of mind characterized by specific levels of cognitive, emotional and behavioral activity in direct brand interactions"(Hollebeek, 2011). Jochen Wirtz et al (2013) mentions that Brand engagement is a new term or an area that needs to be worked on. Identification of the reason for emotional attachment and obsession to certain things can give smart insights to brand managers to apply the same strategies to create brand engagement. Traditional methods to study this concept may not be appropriate as Kazakulova Y. \& Kuhn E. (2012) mention, "Businesses should not expect Brand Engagement to increase by utilizing only the traditional strategies." This makes the current study more relevant to learn how to enhance engagement. People have been obsessed with video games since their inception. This engagement needs to be studied to find out how a game creates a link or connection with the games they play. This study also provides ways to brand managers to think and come up with new ideas so to create the same engagement among consumers regarding brands.

\section{Scope of the Study}

Although this research study is limited to Pakistan, but video games are played in developing and developed world as well. Therefore the scope of the study is quite wide as it gives directions to brand managers not only in in Pakistan but to 
the brand managers of all multinational companies operating in Pakistan and beyond.

\section{Research Methodology}

The study employs exploratory research methodology, as the concept of brand engagement is an emerging one in the marketing literature. (Hollebeek L., 2011), the methodology uses observation and in-depth interviews for data collection and purposive sampling technique was used to select respondents. The data was collected in the natural settings of the players. The natural settings allow having a clear and uninfluenced picture as to why people are so deeply involved with games. The universe for this study is the population of Karachi, Pakistan. Individual males in the age bracket of 18-25 were the sampling unit. The research employs purposive sampling and a total of 50 individuals were the participants of the study. The research involved in depth interviews and observation. A semi-structured questionnaire was used that consisted of open-end and closed-end questions.

\section{Theoretical Underpinnings}

Michele D. dickey (2005) concluded that although video games are a form of entertainment but still their main purpose is to get the people involved in them. This research is about the engagement of men in video games and how can that obsession be used to create brand engagement. Games designers are well aware of creating scenarios that invoke the required skills from the players so they can analyze and use critical skills to play the game.

Bruckman's $(1993,1997)$ and Turkle's $(1995)$ research exposed that the virtual setting allows the game players to play and experiment in a safe and non-threatening environment whereby they can discover different aspects such as challenge, interactivity, user control and pleasure. O'Brien, H.L. \& Toms, E.G. (2008) discussed different Attributes of engagement as suggested by previous researches. They discussed that gamers are engaged because of attention, challenge, feedback, interactivity, perceived user control and pleasure. Aesthetic appeal, endurability, sensory appeal and variety/novelty did not contribute towards players' engagement towards the game. According to Prensky (2001), environment that requires the individuals to dig out meaning of symbols and to read the visual environment is more attractive and such video games create engagement. Csikszentmihalyi and Lawson's (1980) investigation revealed that these games give the players deep concentration, challenges and skills, contentment and control. One more very important insight drawn by Provenzo's (1991) research revealed that there are some games which are goal oriented and with a very few consequences become appealing to the game players. So it is not just the players' psychology that is the reason but the whole strategy that works in order to get the game players engage in games. John, $M$ (n.d.) mentions that a game fosters high level of engagement using a total package. The package goes beyond the physical and visible elements of the game. The game establishes the engagement by creating a virtual domain that is not found in the physical world. The game makes the player in the virtual world.

Video game addiction allows people to use the virtual fantasy world to connect with real people as a substitution for real life human connection. As Bruckman (1997) investigated that males find video games a way to connect with different people. Gaming provides a forum to men to demonstrate their skills and competence by applying control and mastery. The players find playing video games masculine in nature. These factors were considered to be the main factor for their involvement in games by Dickey (2005).

Three factors were considered to be the main reason for players' engagement in the games. First Holbrook et al (1996) mentioned that 'feeling of dominance in a playful environment' is an important factor for players. This factor has been studied extensively and holds good reliability and validity. It is this feeling of victory (dominance) that men have over others while they play video games because it enables them to use their skills and competence and dominate others. Second key variable is Masculinity. DiSalvo et al (2009) and Kirkland, E (2009) discussed the role of Masculinity as a cultural force in game and discuss that players construct their masculinity through the masculine activities in the games such as - fighting, collecting weaponry, exploring and dominating space. Players feel proud to tell it to others because it's a men's thing. The third variable under study is the Social interaction as investigated by Bruckman (1997). Men have a different way of interacting, calling over friends at home and playing video games is one of their ways of interaction. McAllister et al (2012) conducted a study using Bartle's test of gamers' psychology. They identified that socialization is an important aspect of game design. They identified socializer as a gamer category, these gamers do not play the game because it interests them, and their main purpose is to socialize. The gaming industry provides them an opportunity to socialize by playing with each other sitting at their homes online. Bruckman (1997) and Turkle (1996). The relationship is presented in the Diagram 1 below 


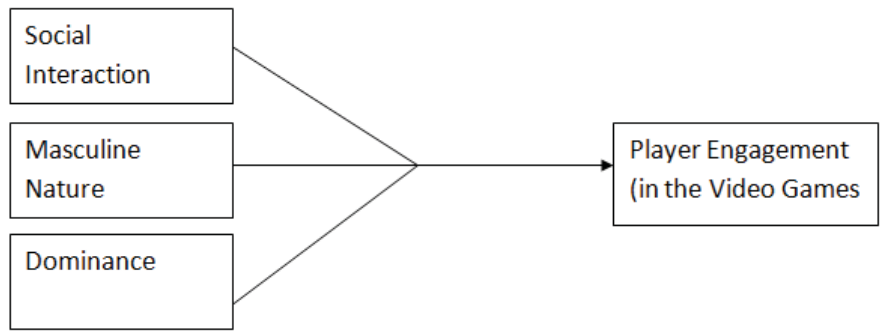

\section{Diagram 01}

\section{Data Analysis and Findings}

Data was collected using observation and in-depth interviews. Observations were made in the natural settings of the players. Players were not told about the purpose of the observation to make unbiased observation. The observation focused on understanding the factors of engagement during the play and players that play at least two hours a day were selected. The findings from observation areas below:

- The gamers were trying to experiment with the game. They were incorporating their physical world learning in the game. For example, a football enthusiast was trying to apply his football playing knowledge from the ground in the game. The game allowed him to play without restrictions.

- Second finding was the strong urge to win. Electronic games give unlimited number of opportunities to the players to try to win again and again. The urge was strong when two or more players were playing the game.

- Third finding was that the players did not want to be moved away from the game, not even for food or basic necessities. The game seemed so immersive and as discussed earlier, it became a virtual world.

In-depth interviews were conducted to comprehend the gamers' understanding of their engagement. The findings are as below;

- First, the game design and features are the most important factor that captre their attention and urges them to play the game.

- Second, the game allows to play beyond the limits of the physical world.

- Third, the games allow a social platform to link with other players and enables the player to exhibit their performance.

- The gamers explained the reasons of not moving away from the game and mentioned that moving away gives advantage to the other player in better understanding the game in their absence and they could lose the game.

Observation and in-depth interviews were followed by a survey to quantify the findings.

A descriptive analysis of the survey findings is given as below:

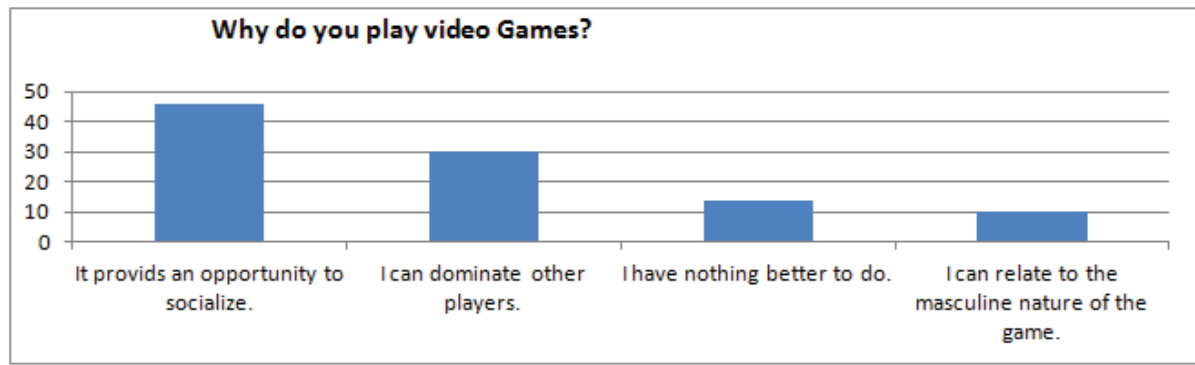

\section{Chart 01}

Chart 01 shows that out of 50 respondents, $46 \%$ of them say that they play games to socialize with their friends. These games allow them to have multiple players and they can play and compete with each other online. Whereas $30 \%$ of the respondents say that it gives them dominance over other players. 


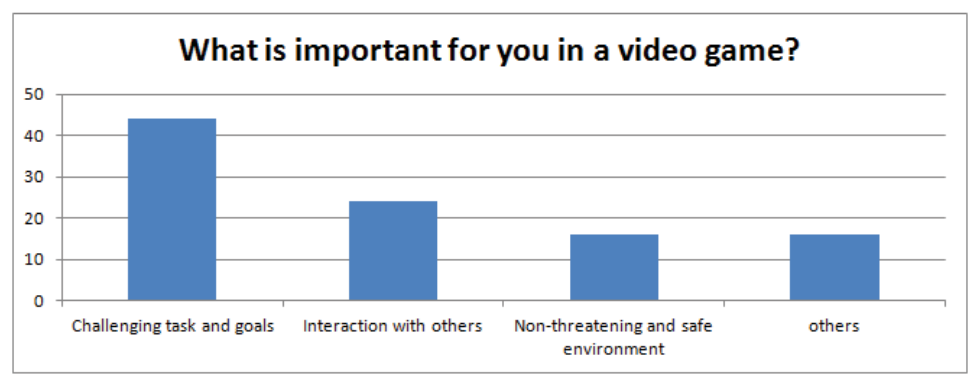

\section{Chart 02}

Chart 02 shows that $44 \%$ of the total respondents look for challenging tasks and goals when they are playing video games; it's the game itself, which becomes interesting and attractive for them when they strive to achieve some target. $24 \%$ of the respondents say that they want the game to play with others so it has to be multi-players game.

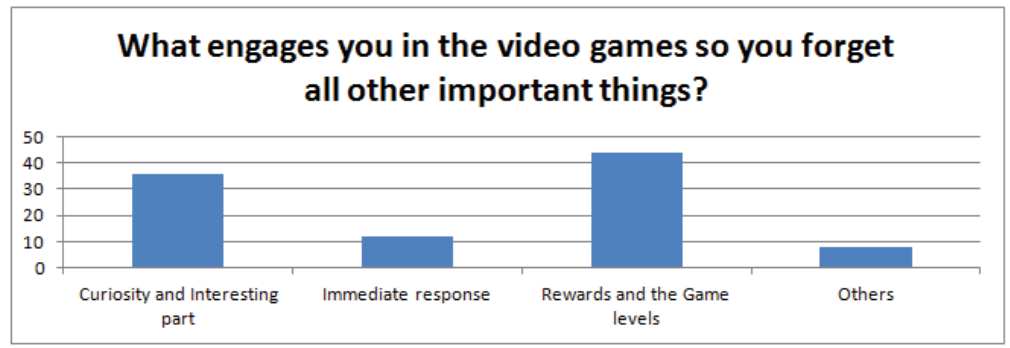

\section{Chart 03}

Chart 03 shows that $44 \%$ of the respondents are engaged in video games because of the rewards and interesting game levels it has. Here the reverse psychology works where you first show the reward and then the individual is motivated to get it. $36 \%$ of the respondents are engaged because of the game's curiosity that it creates.

\section{Discussion and Conclusion}

They key factors that we should consider from the above gathered data are the social interaction, challenging tasks, goals and the curiosity that the game creates. It must be well understood that engagement is a two-way street Kazakulova Y. \& Kuhn E. (2012). It's not only the psychology that is playing its part to engage men in video games but it's also the strategies of the gaming industries that have been successful in attracting its target audience. Patterson et al. (2006) model of engagement discussed vigor, dedication and absorption. It is an appropriate model to apply on gamers as these factors contribute to their immersion in the game. Stanford, D. (2012) discussed the positioning strategy of Mountain Dew brand and considers it be a good example of how brands targeting men should be positioned. Hollebeek (2011) discuss that direct brand interaction means direct physical encounter with the focal brand; games are an engagement subject that provide this interaction to all the players.

The concept of specific types of engagement antecedents, or drivers, is limited to date (Hollebeek, 2011). The earlier theoretical discussion on engagement has focused on the traditional methods, but as discussed in the introduction that the concept of engagement is multidisciplinary with its foundations in psychology, the current study discussed a different perspective for academicians and managers in understanding how brand managers could create engagement among male consumers. Linking the gamers segment with that 'customer based segment/loyalty nexus by segment model' of Hollebeek, the gamers fall in the 'activists' quadrant. It suggests that this segment has a curvilinear engagement loyalty nexus. Lower or no level of engagement in games does not develop loyalty. Strong loyalty is developed when the gamers are an activist group. This makes the gamer type market segment a desirable segment in any company's market base. Wright (2008), however, discussed that activists are prone to emotional fatigue. The overexcitement that this group has with the object of engagement and the direct interaction reduces the propensity of the engagement subject to re-patronize. Any brand targeting the male gamer type segment needs to keep introducing higher 
level of excitement to avoid this fatigue. The feeling of power, dominance and opportunity to socialize should be the main elements of the positioning strategy.

\section{References}

Bowden, J.L.H. (2009). The process of customer engagement: A conceptual framework. Journal of Marketing Theory and Practice, $17(1), 63-74$.

Brodie R.J. et al, (2011) Consumer engagement in a virtual brand community: An exploratory analysis, Journal of Business Research

Bruckman, A. (1993). Community support for constructivist learning. Computer Supported Cooperative Work, 7, 47-86.

Bruckman, A. (1997). MOOSE Crossing: Construction, community, and learning in a networked virtual world for kids. Doctoral dissertation, MIT.

Csikszentmihalyi, M. (1990). Flow: The psychology of optimal experience. New York: Harper \& Row.

Csikszentmihalyi, M., \& Lawson, R. (1980). Intrinsic rewards in school crime. In M. Verble (Ed.), Dealing in discipline. Omaha: University of Mid-America.

Dickey, M.D (2005) Engaging By Design: How Engagement Strategies in Popular Computer and Video Games Can Inform Instructional Design, , ETR\&D, Vol. 53, No. 2

DiSalvo , B.J. (2009) Gaming Masculinity: Video games as a reflection on masculinity in Computer Science and African American culture, unpublished thesis, School of Interactive Computing, Georgia Institute of Technology

Frank, F.D., Finnegan, R.P., \& Taylor, C.R. (2004). The race for talent: Retaining and engaging workers in the 21st century. Human Resource Planning, 27(3), 12-25.

Giselle, A. (2012), How brands define Engagement retrieved from http://www.digiday.com/brands/how-brands-define-engagement/ , retrieved on June 13,2013

Greenwood, M. (2007). Stakeholder engagement: Beyond the myth of corporate responsibility. Journal of Business Ethics, 74(4), 315327.

Holbrook, M.B Chestnut,R.W., Oliva, T.A,. and Greenleaf, E.A. (1984) Play as a Consumption Experience: The Roles of Emotions, Performance, and Personality in the Enjoyment of Games Journal of Consumer Research, Vol. 11, No. 2 , pp. 728-739

Hollebeek, L.D. (2011): Demystifying customer brand engagement: Exploring the loyalty nexus, Journal of Marketing Management, $27: 7-8,785-807$

li'́c, A. (2008). Towards a conceptualisation of consumer engagement in online communities: A netnographic study of vibration training online community. Unpublished master's thesis, University of Auckland (Department of Marketing), Auckland, New Zealand.

Jones, M. (n.d.) Creating Engagement in Computer-based Learning Environments ITForum Paper 30, http://itforum.coe.uga.edu/paper30/paper30.html retrieved on June 27, 2013

Kahn, W.A. (1990). Psychological conditions of personal engagement and disengagement at work. Academy of Management Journal, 33(4), 692-724.

Kazakulova Y. \& Kuhn E. (2012) Communication Strategies via Social Media :The case study of Tomorrowland , Unpublished Master's Thesis, Jonkoping International Business School, Sweden

Kirkland , E. (2009) 'Masculinity in Videogames: The Gendered Gameplay of Silent Hill', Camera Obscura 71, Vol. 24, No. 2, pp. 161183

McAllister et al (2012) Playing to Win? Measuring Social Interaction in Games, http://www.gamasutra.com/view/feature 1134982/playing_to_win_measuring_social_.php?page=2, retrieved on 26 June , 2013

O'Brien, H.L. \& Toms, E.G. (2008). What is user engagement? A conceptual framework for defining user engagement with technology. Journal of the American Society for Information Science \& Technology, 59(6), 938- 955. DOI: 10.1002/asi.20801

Patterson, P., Yu, T., \& De Ruyter, K. (2006, December). Understanding customer engagement in services. Paper presented at ANZMAC 2006 Conference: Advancing Theory, Maintaining Relevance [online], Brisbane, Australia. Retrieved June 27, 2013, from http:// conferences.anzmac.org/ANZMAC2006/documents/Pattinson_Paul.pdf

Prensky, M. (2001). Digital game-based learning. New York: McGraw-Hill.

Provenzo, E. F. (1991). Video kids: Making sense of nintendo. Cambridge, MA: Harvard University Press.

Resnick, E. (2001). Defining engagement. Journal of International Affairs, 54(2), 551-566.

Skinner, E.A., \& Belmont, M.J. (1993). Motivation in the classroom: Reciprocal effects of teacher behavior and student engagement across the school year. Journal of Educational Psychology, 85(4), 571-581.

Stanford, D. (2012)PepsiCo Aims to Bring Urban Cool to Mountain Dew Image: Retail, http://www.bloomberg.com/news/2012-0417/pepsico-aims-to-bring-urban-cool-to-mountain-dew-image-retail.html, retrieved on June 03, 2013

Turkle, S. (1995). Life on the screen: Identity in the age of the internet. Simon \& Schuster: New York.

Wirtz J, et al (2013) Managing brands and customer engagement in online brand communities, Journal of Service Management Vol. 24 No. 3, 2013 pp. 223-244

Wright, R.A. (2008). Drained: Studies of fatigue influence on engagement and associated cardiovascular responses. In L. Sher (Ed.), Psychological factors and cardiovascular disorders (chap. 10). New York: Nova Science. Retrieved June 04 5, 2013, from http:/l www.psy.uab.edu/Wright/Wright-DRAINED.pdf 